\title{
Depressive Symptoms and Perceived Stress among Estate Rubber Tappers in
}

\section{Southern Sri Lanka}

\begin{abstract}
:
Background: Rubber production is an important component of the Sri Lankan economy. Prior reports have raised concerns about poverty and poor physical and social living conditions among rubber tappers. Objective: To assess rubber tappers' psychological health and distress. Methods and Material: A cross-sectional survey was conducted among 300 rubber tappers in two large rubber plantations in southern Sri Lanka from September to November 2014. Structured questionnaires including the Peradeniya Depression Scale (PDS) and the 10-item Perceived Stress Scale (PSS-10) were administered. The prevalences of depression and stress were calculated, including across sociodemographic and work history variables of interest. Results: Each plantation contributed 150 of the 300 participants. The majority were women $(n=183,61 \%)$ with a median age of 47 years (range 21 to 89). Based on the PDS, $9 \%$ of the rubber tappers screened positive for depression. While on the PSS-10, 10\% demonstrated a high level of perceived stress. On log-binomial regression, persons who were widowed, divorced, or separated compared to being married had a higher prevalence of depression and high stress. A higher prevalence of stress was found in Tamil versus Sinhalese as well as Christian versus Buddhist participants. A higher prevalence of depression was seen in workers with over 30 years of experience compared to less experienced counterparts. Conclusions: Depression was more common in rubber tappers in this study than among other non-plantation Sri Lankan populations. Further research is needed to elucidate factors associated with psychological distress and to foster support mechanisms for the rubber tappers.
\end{abstract}

Key Words: Depression, perceived stress, psychosocial issues, rubber tappers, Sri Lanka

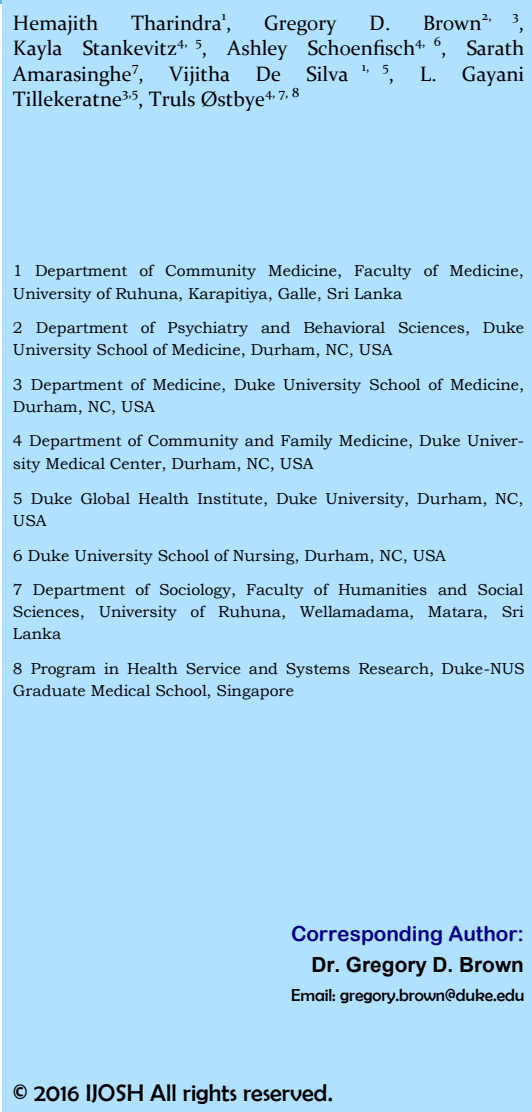

1 Department of Community Medicine, Faculty of Medicine, University of Ruhuna, Karapitiya, Galle, Sri Lanka

2 Department of Psychiatry and Behavioral Sciences, Duke University School of Medicine, Durham, NC, USA

3 Department of Medicine, Duke University School of Medicine, Durham, NC, USA

4 Department of Community and Family Medicine, Duke University Medical Center, Durham, NC, USA

5 Duke Global Health Institute, Duke University, Durham, NC, USA

6 Duke University School of Nursing, Durham, NC, USA

7 Department of Sociology, Faculty of Humanities and Social Sciences, University of Ruhuna, Wellamadama, Matara, Sri

8 Program in Health Service and Systems Research, Duke-NUS Graduate Medical School, Singapore 
Plantation workers not only face subsistence wages but also unhealthy physical living conditions.[8] Housing typically consists of "line rooms", mostly made of semi-permanent or temporary materials.[6] Prior studies of rubber tappers working in small holding companies in India have demonstrated high levels of indebtedness, dependency on tapping for income, limited access to medical care, substandard living facilities, and for women, the added burden of being culturally expected to perform household work even after a full day of tapping.[7, 9] Similar conditions have been found in other plantation industries, namely tea, in Sri Lanka.[6] Other investigations among plantation workers have raised concern of high rates of alcohol use disorders and domestic violence against women.[6, 10] These poverty and psychosocial conditions serve as precipitating and perpetuating factors for mental distress. A study of palm plantation workers in Malaysia demonstrated that over $25 \%$ of these workers had anxiety or depression.[11]

While rubber tappers represent a vulnerable population, little is known about their prevalence of mental distress. We sought to address this knowledge gap by conducting structured interviews of rubber tappers in the Galle district of Sri Lanka. The prevalences of depression and high stress were calculated, and sociodemographic and work history predictors of these outcomes were assessed.

\section{Methods}

\section{Study Design and Population:}

A cross-sectional study was conducted in southern Sri Lanka from September to November 2014. The target population was current rubber tappers who work on plantations in the Galle district. Based on 2015 data, there are three major RPCs according to Plantation Human Development Trust (PHDT) in the Galle district: Elpitiya Plantation with 7 estates and 2031 laborers, Watawala Plantation with 4 estates and 1806 laborers, and Namunukula Plantation with 3 estates and 713 laborers.[4] Three estates from each of two privately owned plantations, here named Plantation $A$ and Plantation $B$, encompassed the sampling frame.

Any worker over 16 years of age, employed by one of the two plantations, and having more than 1 year experience as a rubber tapper was eligible to participate in the study. Permission to interview the rubber tappers was obtained by a manager at the respective plantation. The plantation managers informed rubber tappers of the study prior to researchers' arrival but were otherwise not involved in the recruitment process. Written informed consent was obtained. Consent provided assurances stating that participation would not affect the participants' employment and that managers would not be informed of participation. As employment lists and contact information for the rubber tappers were not available, a convenience sample was selected. Ethical approval for the study was obtained from the Institutional Review Boards of the University of Ruhuna and Duke University.

\section{Data Collection and Scales:}

Participants engaged in structured interviews, which were conducted by researchers reading questions and recording participants' responses. Data were collected on demographic and social factors and work history. Participants completed the Peradeniya Depression Scale (PDS) and 10-item Perceived Stress Scale (PSS-10).

The PDS was designed and validated in Sri Lanka and takes into account cultural expressions and idioms of illness. The scale asks about symptoms in the preceding two weeks. A score equal to or above $10 / 25$ based on previous studies correlates with a clinical diagnosis of depression with a sensitivity of $88.5 \%$ and specificity of $85.0 \%$.[12]

The PSS-10 is a 10-item measure designed to assess the degree to which situations in life have been perceived as stressful in the last month with each item scored on a 5-point Likert scale from 0 (never) to 4 (very often).[13, 14] The item scores are summed to give a total score ranging from 0-40. Data from a 2006 U.S. sample found a mean (standard deviation) score of 12.7 (7.3)[15] which is similar to means obtained in validation studies of the PSS-10 in other countries.[16-18] Data among medical students in Sri Lanka have demonstrated similar results to U.S. studies as well.[19] A score of 20 (representing one standard deviation above the mean in these prior normative studies) or greater was used to indicate high stress. While other studies using the PSS-10 in Sri Lanka have had means ranging from 15.3 to $19.6[20-22]$, a cut-off of 20 has also been used to indicate high stress levels in one of those studies.[20]

\section{Analysis:}

Descriptive analysis was first conducted to determine the prevalence of subjects with a positive screen for depression based on the PDS or with high stress levels based on the PSS-10. Log-binomial regression was used to assess the prevalence of outcomes of interest across covariate categories. Statistical analysis for means and standard deviations was completed with SPSS while prevalence ratios and $95 \%$ confidence intervals $(\mathrm{Cl})$ were calculated using SAS software.

\section{Results}

\section{Subject characteristics:}

A total of 150 rubber tappers were recruited from Plantation A and Plantation $B$ each. The majority of participants were women ( $n=183,61.0 \%$ ) (Table $\mathrm{l}$ ). Most were between the ages of 36-55 years with a median age of 47 years and range from 21 to 89 years. Typical retirement age in Sri Lanka is 55 years, yet $19.7 \%$ of the rubber tappers were older than 55 . $A$ majority $(n=$ $270,90.0 \%)$ were married. Almost one-quarter ( $n=71,23.7 \%)$ had no formal schooling. The literacy rate of rubber tappers was $65 \%$ compared to a rate of $92 \%$ for Sri Lanka nationwide.[23] There were also disproportionately more persons of Tamil descent $(57 \%)$ compared to the average across the Galle district 
(2\%); for Sinhalese decent, this difference was $43 \%$ versus $94 \%$. [24]

A majority $(n=202,67.3 \%)$ had monthly household incomes below the government-calculated approximate household expenditures. A large proportion of participants had started working as rubber tappers before the age of 20 years $(n=125$, $41.7 \%)$ and a majority before 30 years $(n=242,80.7 \%)$. Twenty-five percent $(n=75)$ had been working for over 30 years as rubber tappers.

\section{Prevalence of Depression and Perceived Stress:}

Nine percent $(n=27)$ of the study population screened positive for depression based on the scale cut off of 10/25 questions answered in the affirmative (Table 2).
It was notable that the frequency of reported somatic symptoms was high ranging from $17.0 \%(n=51)$ for fullness of the abdomen and faintishness, to $18.0 \%(n=54)$ for chest ache or palpitations, $37.0 \%(n=111)$ for headache, and $51.3 \%(n=$ 154) for aches of the arms or legs (Table II). On the PDS, $38.3 \%(n=115)$ reported sadness (dukka). Fourteen percent ( $n$ $=42$ ) reported distress-low mood (bade gindera). Literally translated bade gindera means "fire in the abdomen." It is an idiomatic expression that carries a connotation of more severe depression. Moreover, 9.7\% ( $n=29)$ endorsed suicidal ideation, at least passive suicidal ideation, by indicating that they felt there was no point in living anymore.

Table I: Distribution of study cohort across sociodemographic and work history variables, with frequencies, prevalences, prevalence ratios, and $95 \%$ confidence intervals $(\mathrm{Cl})$.

\begin{tabular}{|c|c|c|c|c|c|c|c|c|c|c|}
\hline & & & \multicolumn{4}{|c|}{ Depression } & \multicolumn{4}{|c|}{ High stress } \\
\hline & \multicolumn{2}{|c|}{$\mathrm{n}(\%]$} & $\begin{array}{l}\text { Positive } \\
\text { Screen }\end{array}$ & Prevalence & Preve & $\begin{array}{l}\text { ce ratio }(95 \% \\
\mathrm{Cl})\end{array}$ & $\begin{array}{l}\text { Positive } \\
\text { Screen }\end{array}$ & Prevalence & Preva & $\begin{array}{l}\text { ce ratio }(95 \% \\
\mathrm{Cl})\end{array}$ \\
\hline \multicolumn{11}{|l|}{ Estate Company } \\
\hline Plantation A & 150 & $(50.0)$ & 11 & 0.07 & 1.00 & & 19 & 0.13 & 1.00 & \\
\hline Plantation B & 150 & $(50.0)$ & 16 & 0.11 & 1.45 & $(0.70-3.03)$ & 21 & 0.14 & 1.11 & $(0.62-1.97)$ \\
\hline \multicolumn{11}{|l|}{ Gender } \\
\hline Female & 183 & $(61.0)$ & 18 & 0.10 & 1.00 & & 26 & 0.14 & 1.00 & \\
\hline Male & 117 & $(39.0)$ & 9 & 0.08 & 0.78 & $(0.36-1.68)$ & 14 & 0.12 & 0.84 & $(0.46-1.50)$ \\
\hline \multicolumn{11}{|l|}{ Age } \\
\hline $16-35$ years & 62 & $(20.7)$ & 2 & 0.03 & 0.34 & $(0.08-1.43)$ & 7 & 0.11 & 0.78 & $(0.36-1.70)$ \\
\hline $36-55$ & 179 & $(59.7)$ & 17 & 0.09 & 1.00 & & 26 & 0.15 & 1.00 & \\
\hline Over 55 & 59 & $(19.7)$ & 8 & 0.14 & 1.43 & $(0.65-3.14)$ & 7 & 0.12 & 0.82 & $(0.37-1.78)$ \\
\hline \multicolumn{11}{|l|}{ Education Level } \\
\hline No Schooling & 71 & $(23.7)$ & 7 & 0.10 & 1.06 & $(0.47-2.42)$ & 8 & 0.11 & 0.75 & $(0.36-1.54)$ \\
\hline Grade $01-10$ & 205 & $(68.3)$ & 19 & 0.09 & 1.00 & & 31 & 0.15 & 1.00 & \\
\hline$>$ Grade 10 & 24 & $(8.0)$ & 1 & 0.04 & 0.45 & $(0.06-3.21)$ & 1 & 0.04 & 0.28 & $(0.04-1.93)$ \\
\hline \multicolumn{11}{|l|}{ Literacy Level } \\
\hline Illiterate & 105 & $(35.0)$ & 10 & 0.10 & 1.00 & & 13 & 0.12 & 1.00 & \\
\hline Literate & 195 & $(65.0)$ & 17 & 0.09 & 0.92 & $(0.43-1.93)$ & 27 & 0.14 & 1.12 & $(0.60-2.07)$ \\
\hline \multicolumn{11}{|l|}{ Ethnicity } \\
\hline Sinhalese & 129 & $(43.0)$ & 10 & 0.08 & 1.00 & & 11 & 0.09 & 1.00 & \\
\hline Tamil / Other & 171 & $(57.0)$ & 17 & 0.10 & 1.28 & $(0.61-2.71)$ & 29 & 0.17 & 1.99 & $(1.03-3.83)$ \\
\hline \multicolumn{11}{|l|}{ Religion } \\
\hline Buddhist & 135 & $(45.0)$ & 10 & 0.07 & 1.00 & & 12 & 0.09 & 1.00 & \\
\hline Hindu / Muslim & 126 & $(42.0)$ & 12 & 0.10 & 1.29 & $(0.58-2.87)$ & 20 & 0.16 & 1.79 & $(0.91-3.50)$ \\
\hline Christian & 39 & $(13.0)$ & 5 & 0.13 & 1.73 & $(0.63-4.76)$ & 8 & 0.21 & 2.31 & $(1.02-5.24)$ \\
\hline \multicolumn{11}{|l|}{ Marital Status } \\
\hline Unmarried & 9 & $(3.0)$ & 0 & 0.00 & -- & -- & 0 & 0.00 & -- & \\
\hline Married & 270 & $(90.0)$ & 21 & 0.08 & 1.00 & & 33 & 0.12 & 1.00 & \\
\hline Separated ${ }^{*}$ & 21 & $(7.0)$ & 6 & 0.29 & 3.67 & $(1.67-8.10)$ & 7 & 0.33 & 2.73 & $(1.38-5.41)$ \\
\hline \multicolumn{11}{|l|}{ Monthly Household Income } \\
\hline$<15000$ SLRs $[<115$ USD] & 43 & $(14.3)$ & 7 & 0.16 & 1.73 & $(0.75-3.96)$ & 9 & 0.21 & 1.39 & $(0.70-2.76)$ \\
\hline $15001-30000[115-230]$ & 159 & $(53.0)$ & 15 & 0.09 & 1.00 & & 24 & 0.15 & 1.00 & \\
\hline$>30001[>230]$ & 98 & $(32.7)$ & 5 & 0.05 & 0.54 & $(0.20-1.44)$ & 7 & 0.07 & 0.47 & $(0.21-1.06)$ \\
\hline \multicolumn{11}{|l|}{ Work Started Age } \\
\hline below 20 years & 125 & $(41.7)$ & 12 & 0.10 & 1.00 & & 20 & 0.16 & 1.00 & \\
\hline $21-30$ & 117 & $(39.0)$ & 9 & 0.08 & 0.80 & $(0.35-1.83)$ & 12 & 0.10 & 0.64 & $(0.33-1.25)$ \\
\hline over 30 & 58 & $(19.3)$ & 6 & 0.10 & 1.08 & $(0.43-2.73)$ & 8 & 0.14 & 0.86 & $(0.40-1.84)$ \\
\hline \multicolumn{11}{|l|}{ Working Duration } \\
\hline $1-10$ years & 76 & $(25.3)$ & 3 & 0.04 & 0.20 & $(0.06-0.65)$ & 11 & 0.14 & 1.09 & $(0.49-2.40)$ \\
\hline $11-30$ years & 149 & $(49.7)$ & 9 & 0.06 & 0.30 & $(0.14-0.66)$ & 19 & 0.13 & 0.96 & $(0.47-1.95)$ \\
\hline$>30$ & 75 & $(25.0)$ & 15 & 0.20 & 1.00 & & 10 & 0.13 & 1.00 & \\
\hline
\end{tabular}

Total sample ( $\mathrm{n}$ ) equals 300. Percentages refer to within row based on that demographic variable. *Separated includes widowed, divorced, or separated individuals. SLRs indicates Sri Lankan rupees. USD indicates United States dollars. Percentages do not always total $100 \%$ due to rounding. 
Table II. Responses to the Peradeniya Depression Scale items among rubber tappers in Galle District, Sri Lanka, 2014.

\begin{tabular}{|c|c|c|}
\hline Peradeniya Depression Scale Questions & Yes Responses & Percentage (\%) \\
\hline Have you been experiencing burning pains of your body? & 31 & 10.3 \\
\hline Have you been having difficulty sleeping at night? & 58 & 19.3 \\
\hline Have you lost weight without an obvious illness? & 24 & 8.0 \\
\hline Have you been experiencing loss of appetite? & 32 & 10.7 \\
\hline \multicolumn{3}{|l|}{ Have you often been experiencing any of the following? } \\
\hline Headache & 111 & 37.0 \\
\hline Aches of the arms or legs & 154 & 51.3 \\
\hline Aches of the body (waatha amaaruwa) & 64 & 21.3 \\
\hline Fullness of the abdomen & 51 & 17.0 \\
\hline Faintishness & 51 & 17.0 \\
\hline \multicolumn{3}{|l|}{ Have you been suffering from any of the following? } \\
\hline Sadness (dukka) & 115 & 38.3 \\
\hline Have you been feeling sad that there is no point in living anymore? & 29 & 9.7 \\
\hline Have you been fearful about the future of yourself or your family? & 77 & 25.7 \\
\hline Have you felt uncertain, or felt less confident in yourself? & 36 & 12.0 \\
\hline Have you felt suspicious at times? & 22 & 7.3 \\
\hline \multicolumn{3}{|l|}{ Have you been worrying that the above difficulties are due to any of the following? } \\
\hline Due to the effect of a previous karma & 83 & 27.7 \\
\hline Because of an astrologically bad period & 81 & 27.0 \\
\hline Because of evil charms cast against you & 20 & 6.7 \\
\hline Have you been unable to attend to your usual every day work at home? & 38 & 12.7 \\
\hline
\end{tabular}

Number of positive responses to the sub-items on the Peradeniya Depression Scale with percentage of positives responses among 300 rubber tappers in the Galle District, Sri Lanka. Questions correspond to symptoms over the previous two weeks. A positive screen for depression equals a score of 10 or higher on the scale.

Based on a cut-off of $20 / 40$ on the PSS-10, $10.0 \%(n=30)$ of the rubber tappers were classified as having high stress. Results from PSS-10 screening are provided in Table 3. The mean score was 14.6 (range of 5 to 30 ) with a standard deviation of 4.4. The most commonly endorsed items dealt with the sense of inability to control important things or irritations in life (Table III).

\section{Factors Associated with Depression and High Perceived Stress:}

In examining the prevalence of outcomes of interest across covariate categories, those who were widowed, divorced, or separated had a higher prevalence of both depression (PR 3.67, $95 \% \mathrm{Cl} 1.67-8.10$ ) and high stress (PR 2.73, 95\% Cl 1.38-5.41) compared to those who were married (Table I). The prevalence of depression was higher among those with more than 30 years of experience compared to their less veteran counterparts. The prevalence of high stress was higher among those persons of Tamil or other ethnicity compared to Sinhalese (PR 1.99, 95\% Cl
1.03-3.83) as well as among Christians compared to Buddhists (PR 2.31, 95\% Cl 1.02-5.24).

\section{Discussion}

We surveyed rubber tappers in two plantations in the Galle district of Sri Lanka and found a prevalence of depression (9\%) higher than what have been reported in other parts of Sri Lanka.[25, 26] Our study findings contrast to a lifetime prevalence for depression of $6.6 \%$ in prior studies based on an interview sample in Colombo, Sri Lanka using Diagnostic and Statistical Manual IV (DSM-IV) criteria [25] or to a point prevalence of $4.5 \%$ for major depression $(13.3 \%$ for mild depression) based on screening with the Patient Health Questionnaire (PHQ-9) in primary care settings in the Northern Province of Sri Lanka.[26] However, mean stress levels were similar to or lower than those in prior studies in Sri Lanka populations, albeit most prior studies examined students at various levels of education making direct comparisons more difficult.[19-22] 
Table III. Responses to items on the Perceived Stress Scale.

\begin{tabular}{|c|c|c|}
\hline Perceived Stress Scale Stress Questions & Mean & $\begin{array}{l}\text { Standard } \\
\text { Deviation } \\
\text { (SD) }\end{array}$ \\
\hline \multicolumn{3}{|c|}{ In the past month, how often have you... } \\
\hline $\begin{array}{l}\text {..been upset because of something that happened } \\
\text { unexpectedly? }\end{array}$ & 1.33 & 0.83 \\
\hline $\begin{array}{l}\text {.felt that you were unable to control the important } \\
\text { things in your life? }\end{array}$ & 2.01 & 0.94 \\
\hline ...felt nervous and "stressed"? & 1.46 & 0.87 \\
\hline $\begin{array}{l}\text {...felt confident about your ability to handle your } \\
\text { personal problems? }\end{array}$ & 1.11 & 0.65 \\
\hline ...felt that things were going your way? $\neq$ & 1.27 & 0.65 \\
\hline $\begin{array}{l}\text {...found that you could not cope with all the things } \\
\text { that you had to do?* }\end{array}$ & 1.52 & 0.84 \\
\hline ...been able to control irritations in your life ?* & 1.69 & 0.97 \\
\hline felt that you were on top of things? $\neq$ & 1.27 & 0.68 \\
\hline $\begin{array}{l}\text {...been angered because of things that were outside } \\
\text { of your control? } \neq\end{array}$ & 1.46 & 0.74 \\
\hline 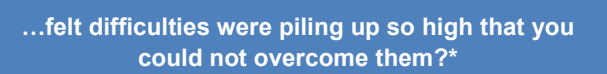 & 1.48 & 0.84 \\
\hline Total & 14.60 & 4.39 \\
\hline
\end{tabular}

Mean responses to 10 -item Perceived Stress Scale among 300 rubber tappers in the Galle District, Sri Lanka.

$\mathrm{N}=300$ except 299 for questions 6,7 , and 10 denoted by * and 298 for questions 5,8 , and 9 denoted by $\neq$ Missing data points are due to survey questions left blank.

Even with a prevalence of depression at $9 \%$, the burden of depression may be underrepresented in the sample. A similar percentage $(9.7 \%)$ endorsed some level of suicidal ideation and over $38 \%$ endorsed sadness. It is likely that the prevalence of major depressive disorder is $9-10 \%$ and that of mild depression is higher based on these results. Future studies will be needed to find out why rubber tappers potentially have a higher prevalence of depression than other populations in Sri Lanka. However, there are several possible explanations. One is poverty and poor physical living conditions. Another is poor general health: we have previously found an association between depressive symptomatology and musculoskeletal disorders.[3] However, whether depressive symptoms exacerbate or are driven by musculoskeletal symptoms among rubber tappers is less clear. A reciprocal relationship between the two is plausible.

Within the population of rubber tappers, musculoskeletal disorders may also help explain why rubber tappers who had worked longer in the rubber industry had a higher prevalence of depression. Rubber tapping is physically demanding work, often requiring awkward body positions, exposing workers to the risk of musculoskeletal injuries and pain.[3] Chronic pain has been associated with increased risk of depression and anxiety across global populations.[27, 28] The higher frequency of depression in rubber tappers working in the industry for over 30 years may also reflect on limited social mobility and continued low socioeconomic status.[29] As laborers work towards retirement, the lack of socioeconomic advancement could have untoward effects on depressive symptomatology.

We found that persons who were widowed, divorced, or separated had an over 3.5 greater prevalence of depression and an over 2.5 times greater prevalence of high stress. Participants who were Tamil had a higher prevalence of high stress compared to Sinhalese and likewise between participants who were Christian compared to Buddhist. The increased prevalence of depression and high stress among widowed, divorced, or separated rubber tappers could be explained by lack of social support relative to married peers. Among the small number of unmarried workers, there were no positive screens. Although it is difficult to draw definitive conclusions, other factors such as abuse within that prior relationship, grieving over loss of spouse, or decreased social status among divorced or separated individuals may also contribute to high stress and depression in that group. The higher prevalence of high stress among persons of Tamil decent is in line with other studies in Sri Lanka showing an association between minority status and depression and anxiety, respectively,[30] albeit the association in our study existed for stress and not depression. The higher prevalence of perceived stress among Christians compared to Buddhists may relate to expressions of stress or handling of stress within those religions.

We see the above relationships while also acknowledging the wide confidence intervals for many of the prevalence ratios and therefore the instability of the estimates. Further limitations exist in confirmation of the sample as representative of rubber tappers as a whole. Although the participants had explicit verbal reassurance that the study would not affect their job status, the possible effect of underreporting of symptoms for fear of job security is not known. Given the absence of employment lists or contact information for the rubber tappers, it is possible that the participants were not representative of the underlying source population. The participants may have a lower occurrence of psychosocial stress than their non-participating co-workers as the participants were available and willing to participate.

The term depression has been used throughout, but it should be noted that the PDS is a screening instrument for depressive symptomatology even if a score at or above 10 has been shown elsewhere to correlate well with clinician-diagnosed depression.

Despite the limitations, the study did include two of the largest rubber plantations in southern Sri Lanka and surveyed multiple estates within each plantation. We also used a validated, culturally-specific scale for depression and a scale for stress that has also been validated in multiple south Asian countries. Moreover, the very limited missing data is a significant strength in studying this vulnerable and typically hard-to-reach population.

These results add to the limited knowledge on the health status of rubber tappers. 


\section{Conclusion}

The prevalence of depression among rubber tappers is higher than among other examined populations in Sri Lanka. Conversely, the proportion reporting a high stress level is similar to those in other populations. Being widowed, divorced, or separated appears to increase rubbers tappers risk of depression and high stress compared to married workers. Work duration over 30 years is associated with a higher prevalence of depressive symptomatology, while Tamil or Christians persons had a higher prevalence of high stress compared to Sinhalese or Buddhists respectively. Future research can help understand these associations for depression and high stress levels. Further exploration is needed to elucidate factors associated with psychological distress and to foster psychosocial support mechanisms for the rubber tappers.

\section{References}

1. Central Bank of Sri Lanka. Economic and social statistics of Sri Lanka 2012. Vol 34. Colombo, Sri Lanka: Central Bank Printing Press, 2012.

2. Rubber Reaseach Institute. Key indicators: rubber and rubber extent in different districts. Rubber Research Institure of Sri Lanka Statistics 2016; http://www.rrisl.lk/sub_pags/statistics.html. $\quad$ Accessed 4 May 2016.

3. Stankevitz K, Schoenfisch A, de Silva V, Tharindra H, Stroo M, Ostbye T. Prevalence and risk factors of musculoskeletal disorders among Sri Lankan rubber tappers. Int J Occup Environ Health. 2016: 1-8.

4. Plantation Human Development Trust. Regional office - Galle plantation data. E-mail Communication, June 2016

5. The World Bank. Offical exchange rate (LCU per US\$, peroid average). 2016; http://data.worldbank.org/indicator/PA.NUS.FCRF. Accessed 5 May 2016

6. Pinawala SK, Karunatissa SA, Razaak MGM, Pinawalla M, Kamalrathne WGCT, Sivakanthan S, et al. The plantation sector in transition: research on the upcountry plantation sector in Sri Lanka. University of Perandeniya, 2010.

7. Ushadevi TV, Jayachandran VN. Socio-economic profile of rubber tappers in the small holding sector: a study at Kanjirappally Panch ayath. Thiruvananthapuram: Kerala Research Programme on Local Level Development Centre for Development Studies, 2001.

8. Piyarathne A. Wathukaraya kamkaruwa ha wenaswana jeewana ratawa. (Plantation, worker, and changing livelihoods). Colombo, Sri Lanka: Wijesooriya Publishers, 2005.

9. Anishkumar PT. Socio-economic profile of rubber tappers in the small holding sector: a study at Wardvi of the Vazhoorgrama Kerala. Indian Streams Research Journal. 2014, 4(4).

10. Bitter cup of tea: estate workers struggle to make ends meet. Daily Mirror. 2012; http://www.dailymirror.lk/23078/bitter-cup-of-tea-estate-workers-struggle -to-make-ends-meet-. Accessed 22 April 2016.

11. Leonard JH, Ali JE, Vikram M, Saraswathy V, Hanif FM, Nihayah M, et al. Risk of mental health disorders among farmers involved in palm plantation occupation. La Clinica Terapeutica. 2013;164(5): 403-6.

12. Abeyasinghe DR, Tennakoon S, Rajapakse TN. The development and validation of the Peradeniya Depression Scale [PDS]--a culturally relevant too for screening of depression in Sri Lanka. Journal of Affective Disorders. 2012;142(1-3): 143-9.

13. Cohen S, Kamarck T, Mermelstein R. A global measure of perceived stress. Journal of Health and Social Behavior. 1983;24(4): 385-96.

14. Cohen S, Williamson G. Perceived stress in a probability sample of the United States. In: Spacapan S, Oskamp S, editors. The Social Psychology of Health. Newbury Park, CA: Sage, 1988.

15. Cohen S, Janicki-Deverts D. Who's stressed? Distributions of psychological stress in the United States in probability samples from 1983, 2006, and 2009 Journal of Applied Social Psychology. 2012;42: 1320-34.

16. Andreou E, Alexopoulos EC, Lionis C, Varvogli L, Gnardellis C, Chrousos GP et al. Perceived Stress Scale: reliability and validity study in Greece. International Journal of Environmental Research and Public Health. 2011;8(8): 328798.
17. Leung DY, Lam TH, Chan SS. Three versions of Perceived Stress Scale: validation in a sample of Chinese cardiac patients who smoke. BMC Public Health. 2010;10: 513 .

18. Lee EH, Chung BY, Suh $\mathrm{CH}$, Jung JY. Korean versions of the Perceived Stress Scale (PSS-14, 10 and 4): psychometric evaluation in patients with chronic disease. Scandinavian Journal of Caring Sciences. 2015;29(1): 18392.

19. Somasiri KG, Samaranayake CL, Nissanka CP, Jayawardena AJPM, editors Stress perception among meditators who are affected by tsunami. In the proceedings of the Third Academic Sessions. http://www.ruh.ac.lk/research/ academic_sessions/2006_mergepdf/scan0065.pdf. Accessed 4 May 2016.

20. Wickramarachchi, R (ed). Perceived stress in a sample of G.C.E. [A/L] students in Sri Lankan Schools. In the proceedings of the 9th International Conference on Sri Lanka Studies, Matara, Sri Lanka, 2003. http:// www.slageconr.net/slsnet/9thicsls/fullpapers/fullp016.pdf. Accessed 4 May 2016.

21. Sathess S, Sivapalan K, Sivayokan S. Influence of personal factors on the perceived stress level of students of College of Nursing, Jaffna. In the proceedings of the Abstracts of Jaffna University International Research Conference [JUICE], Jaffna, Sri Lanka, 2012.

22. de Silva MKOK, Liyanage IK, de Silva P, Katulanda P. Prevalence of perceived stress among adolescent school children in Colombo District. http:// www.kdu.ac.lk/faculty-of-medicine/files/research/

Prevalence of Perceived Stress Ms MKOK_De\%20Silva.pdf. Accessed 5 May 2016.

23. Ministry of Higher Education and Highways. Overview. 2012; http:// www.mohe.gov.lk/index.php/en/about-ministry/overview. Accessed 28 April 2016

24. Census of Population and Housing. Number and percentage of population by district and ethnic group. 2001; http://www.statistics.gov.lk/pophousat/pdf/ population/p9p8\%20ethnicity.pdf. Accessed 28 April 2016

25. Ball HA, Siribaddana SH, Kovas Y, Glozier N, McGuffin P, Sumathipala A, et al. Epidemiology and symptomatology of depression in Sri Lanka: a crosssectional population-based survey in Colombo District. Journal of Affective Disorders. 2010;123(1-3): 188-96.

26. Senarath U, Wickramage K, Peiris SL. Prevalence of depression and its associated factors among patients attending primary care settings in the post -conflict Northern Province in Sri Lanka: a cross-sectional study. BMC Psychiatry. 2014;14: 85.

27. Gureje O, Von Korff M, Simon GE, Gater R. Persistent pain and well-being: a World Health Organization Study in Primary Care. JAMA. 1998;280(2): 14751.

28. Sagheer MA, Khan MF, Sharif S. Association between chronic low back pain anxiety and depression in patients at a tertiary care centre. The Journal of the Pakistan Medical Association. 2013;63(6): 688-90.

29. Dal Grande E, Chittleborough CR, Wu J, Shi Z, Goldney RD, Taylor AW. Effect of social mobility in family financial situation and housing tenure on mental health conditions among South Australian adults: results from a population health surveillance system, 2009 to 2011. BMC Public Health. 2015;15: 675.

30. Jayasuriya $D$, Jayasuriya $R$, Tay AK, Silove D. Associations of mental distress with residency in conflict zones, ethnic minority status, and potentially modifiable social factors following conflict in Sri Lanka: a nationwide crosssectional study. The Lancet Psychiatry. 2016;3(2): 145-53. 